\title{
LJOURNAL.RU
}

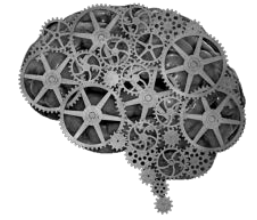

COMPANY GROUP "INTELLEKT"

\author{
Шихова Е.В. \\ Невский Машиностроительный техникум \\ Санкт-Петербург, Россия
}

doi: 10.18411/lj2016-3-102

\section{Carmen 53 Катулла к проблеме датировки}

B Carmen 53, которое является комплиментом ораторскому таланту Гая Лициния Кальва ${ }^{1}$, близкого друга Катулла, поэт живо описывает сцену, разыгравшуюся во время суда над Публием Ватинием² :

«Risi nescioquem modo e corona,

qui, cum mirifice Vatiniana

meus crimina Calvus explicasset,

admirans ait haec manusque tollens:

«di magni, salaputium disertum!» ${ }^{3}$ »

К сожалению, не вполне ясно в какой конкретно год имели место данные события, ведь Лициний Кальв выступал с обвинительной речью против Ватиния

\footnotetext{
${ }^{1}$ Пасколи (Pascoli) «Le Muse», de Agostini, Novara, 1964, Vol.III, P. 6

2 «a political adventurer in the last days of the republic» как он описан в «A new classical dictionary of Greek and Roman biography, mythology and geography» partly based upon the Dictionary of Greek and Roman biography, mythology by William Smith. Rev. With numerous corrections and additions by Charles Anthon. 1860. Harper. New-York. P. 926. Публий Ватиний (как сказано в вышеуказанном источнике) был квестором 63 года до н.э., трибуном плебеев в 59 году до н.э., именно благодаря ему Цезарь получил под управление провинции Цизальпийская Галлия(родина Катулла) и Иллирия; в последствии стал консулом 47 года до н.э.

3 Gaio Valerio Catullo «I Canti» Introduzione e note di Alfonso Traina. Traduzione di Enzo Mandruzzato. Ventiduesima edizione Bur. Classi greci e latini maggio. 2012. Р. 210 «И смеялся же я на днях в собранье:/ Там мой Кальв с удивительным искусством/ Все ватиниевы грехи представил,/ И в восторге всплеснув руками кто-то/ Вдруг вскричал: - «Ну и шиш, каков оратор!» перевод приводится по изданию «Гай Валерий Катулл Веронский. Книга Стихотворений». Издание подготовили С. В. Шервинский M.JL Гаспаров. Москва «НАУКА». 1986. Стр. 32
} 
как минимум три раза в период с 58 по 54 год ${ }^{4}$ до нашей эры. К тому же, в античности репутация Кальва как оратора целиком зиждилась на его речах против Ватиния ${ }^{5}$.

Все доказательства «за» и «против» того, что эта речь имела место в 58 году до нашей эры, были рассмотрены Эрихом С. Грюеном (Erich S.Gruen) в его статье «Cicero and Licinius Calvus» ${ }^{6}$. В 58 году до н.э. Ватинию было предъявлено обвинение в нарушении «Lex Licinia Iunia» ${ }^{7}$, однако из-за вмешательства Публия Клодия процесс не состоялся. Прежде всего, небезынтересным будет отметить, что единственным подтверждением участия Кальва в этом процессе является отметка в рукописи «In Vatinium» Цицерона, сделанная знаменитым схолиастом из монастыря Боббио в VII веке. Комментируя «In Vatinium», этот схолиаст отмечает, что обвинителем был Лициний Кальв ${ }^{9}$, а предметом было нарушение закона «Lex Licinia de sodaliciis» $^{10}$. Очевидно, что схолиаст перепутал «Lex Licinia de sodaliciis», который был принят только в 55 году до н.э. ${ }^{11}$ и «Lex Licinia Iunia».

Корнелий Тацит (P.Cornelius Tacitus) в своем «Dialogus de Oratoribus» ${ }^{12}$ отмечал, что первое публичное выступление Лициния Кальва против Публия

4 «Calvo accuso Vatinio almeno tre volte, tra il 58 e il 54» Gaio Valerio Catullo «I Canti» Introduzione e note di Alfonso Traina. Traduzione di Enzo Mandruzzato. Ventiduesima edizione Bur. Classi greci e latini maggio 2012 P. 211.

${ }^{5}$ Cornelius Tacitus. Dialogus de Oratoribus. 21. и Э.С.Грюен (Erich S.Gruen) «Cicero and Licinius Calvus» Harvard Studies in Classical Philology, Vol. 71, 1967. P. 217.

6 Э.С.Грюен (Erich S.Gruen) «Cicero and Licinius Calvus» Harvard Studies in Classical Philology, Vol. 71, 1967. P. 215.

${ }^{7}$ Cicero. In Vatinium. 14.33. Lex Licinia Iunia был принят для обеспечения соблюдения Lex Caecilia Didia 98 года до н.э. и ужесточал меры, применяемые при нарушении первого. Суть закона заключалась в обеспечении доступности текста населению на уровне законопроекта, записи текста предложенных законов передавались в эрарий.

8 Э.С.Грюен (Erich S.Gruen) в своей статье «Cicero and Licinius Calvus» Harvard Studies in Classical Philology, Vol. 71, 1967. P.217., схолии приводятся по изданию Bobiensia: Neue Beitrager Textkritik und sprache der Bobienser Ciceroscholien. Theodor Stangl. Buchdruckerei von J.B.Lindl, 1984 года.

9 «Наес facta sunt cum reus esset de vi P.Vatinius accusante C.Licinio» схолия к In Vatinium. 34.

10 «Crimine de sodaliciis Vatinius coeperat accusari, de quo puniendo iis legibus cavebatur» схолия к In Vatinium. 33.

${ }^{11}$ Rotondi. Leges Publicae Populi Romani. Milano. 1912. P. 407

12 «Разговор об ораторах» 
Ватиния состоялось, когда первому было не многим больше 22 лет $^{13}$, а Плиний Старший ${ }^{14}$ дает нам 82 год до нашей эры в качестве даты рождения Кальва. Таким образом, получается, что первую обвинительную речь против Ватиния Кальв произнес в 58 году до нашей эры. Однако, как было указано выше, процесс 58 года не состоялся из-за вмешательства Публия Клодия. Стоит отметить, что в той же строке Тацит допускает ошибку, полагая, что «unoetvicesimo <aetatis anno> Caesar Dolabellam» ${ }^{15}$ обвинял, что, естественно, невозможно, учитывая, что Гай Юлий Цезарь родился в 100 году до нашей эры, а дело слушалось не ранее ${ }^{16} 77$ года до нашей эры. ${ }^{17}$ Из всего вышесказанного можно заключить, что Лициний Кальв не мог выступать в качестве обвинителя на этом процессе, и, следовательно, не мог произнести речь против Ватиния в 58 году до нашей эры.

В 56 году до нашей эры Марк Туллий Цицерон и Лициний Макр Кальв объединились для защиты Публия Сестия, процесс против которого был инициирован Гнеем Нерием и Публием Туллием Альбинованом, где Публий

13 «altero et vicesimo $<\ldots>$, non multum aetate antecedens Calvus Vatinium iis orationibus insecuti sunt, quas hodieque cum admiratione legimus» на P. 135 P. Cornelii Taciti ed. Henry Furneaux (Oxford: Clarendon Press, 1900), что переведено как: «на двадцать втором < ..> лишь немного превосходивший его возрастом Кальв - против Ватиния, — и с такими речами, которые и ныне мы читаем все еще с восхищением» в Корнелий Тацит. Сочинения в двух томах. Том I. «Анналы. Малые произведения». Науч.-изд. центр «Ладомир», М., 1993. Издание подготовили А. С. Бобович, Я. М. Боровский, М. Е. Сергеенко. Перевод и комментарий осуществлены А. С. Бобовичем (редакторы переводов - Я. М. Боровский и М. Е. Сергеенко). Общая редакция издания - С. Л. Утченко.

${ }^{14}$ Gaius Plinius Secundus. Naturalis Historia 7. 165.

15 «на двадцать первом <году отроду> - Цезарь против Долабеллы» из Корнелий Тацит. Сочинения в двух томах. Том I. «Анналы. Малые произведения». Науч.-изд. центр «Ладомир», М., 1993. Издание подготовили А. С. Бобович, Я. М. Боровский, М. Е. Сергеенко. Перевод и комментарий осуществлены А. С. Бобовичем (редакторы переводов - Я. М. Боровский и М. Е. Сергеенко). Латинский текст отрывка <34> цитируется по изданию: Р. Cornelii Taciti Dialogus de Oratoribus. ed. Henry Furneaux. Oxford: Clarendon Press. 1900. P. 67.

${ }^{16}$ Цезарь «навлек на себя ненависть всемогущего диктатора Суллы и был вынужден покинуть Италию. Лишь после смерти Суллы в 78 году до нашей эры он смог вернуться в Рим». «Художественная историография древнего Рима» Дуров В.С. СПБ, Издательство СанктПетербургского Государственного Университета. 1993. Стр. 39.

17 Об этом Э.С.Грюен (E.S.Gruen) подробно рассуждает в статье «The Dolabelae and Sulla» (1966 год, AJP 87. Р. 386-389). Кроме того Тацит ошибается приписывая Крассу девятнадцатилетний возраст, тогда как тому на самом деле было двадцать один год.(Cicero.De Orat. 3.74) 
Ватиний выступал в качестве свидетеля со стороны обвинения. Речь Кальва не сохранилась, однако исходя из речи Цицерона ${ }^{18}$, выступавшего на этом процессе последним, и буквально засыпавшего Ватиния обвинениями, мы можем судить об обстановке. Из письма Цицерона к брату Квинту известно, что Сестий был оправдан, Ватиний ушел «смущенным и угнетенным» ${ }^{19}$, а Луций Эмилий Павел «confirmavit se nomen Vatinii delaturum, si Macer Licinius cunctaretur, et Macer ab Sestii subselliis surrexit ac se illi non defuturm affirmavit» ${ }^{20}$.

Корнелий Тацит (P.Cornelius Tacitus) в своем «Dialogus de Oratoribus» пишет, что все изучающие красноречие обращались к обвинительным речам Кальва «quae in Vatinium inscribuntur, ac praecipue secunda ex his oratio; est enim verbis ornata et sententiis, auribus iudicum accommodat» ${ }^{21}$, вероятно, именно по следам этой знаменитой второй речи Катуллом и было написано Carmen 53.

Говард Комфорт (Howard Comfort) в своей статье «The Date of Catullus 53» ${ }^{22}$ оспаривает общепринятую позицию о том, что стихотворение было написано в 56 году до нашей эры. Его главным аргументом является тот факт, что в 56 году Кальв не смог бы выступить с речью против Ватиния (процесс Сестия состоялся 11 марта) позднее 17 апреля (по дореформленному календарю,

18 «Pro Sestio Oratio» - «Речь в защиту Публия Сестия»

19 Ad Quintum Fratrem. 2.4.1. Письма Марка Туллия Цицерона к Аттику, близким, брату Квинту, М. Бруту. Т. I, годы 68-51. Издательство Академии Наук СССР, МоскваЛенинград, 1949. Перевод и комментарии В. О. Горенштейна. Стр.85.

${ }^{20}$ Marcus Tullius Cicero. Select Letters. D. R. Shackleton Bailey. Cambridge University Press, Jul 3, 1980. Biography \& Autobiography. Р. 38 «заявил о своем намерении привлечь Ватиния к суду, если Макр Лициний замедлит с этим, а Макр поднялся со скамьи защитников Сестия и подтвердил, что за ним дело не станет» перевод приводится по изданию Письма Марка Туллия Цицерона к Аттику, близким, брату Квинту, М. Бруту. Т. I, годы 68-51. Издательство Академии Наук СССР, Москва-Ленинград, 1949. Перевод и комментарии В. О. Горенштейна. Стр.85.

21 Tacitus.Dialogus de Oratoribus. 21. The Annals and the Histories (Modern Library Classics) ed. Moses Hadas. 2003. «"Против Ватиния", и особенно вторая из них; в ней есть и слова, и мысли, все, чему полагается быть, и она приспособлена ко вкусам судей» Перевод приводится по изданию Корнелий Тацит. Сочинения в двух томах. Том I. «Анналы. Малые произведения». Науч.-изд. центр «Ладомир», М., 1993. Издание подготовили А. С. Бобович, Я. М. Боровский, М. Е. Сергеенко. Перевод и комментарий осуществлены А. С. Бобовичем (редакторы переводов - Я. М. Боровский и М. Е. Сергеенко). Общая редакция издания - С. Л. Утченко.

22 Говард Комфорт (Howard Comfort) «The Date of Catullus 53» Haverford College. 1935. PP. 764-76 
то есть до 25 марта по юлианскому календарю) ${ }^{23}$. Катулл же в это время должен был находиться в Вифинии в свите Меммия ${ }^{24}$, затем отправиться в Азию к могиле брата, а после этого вернуться на Сирмион. Следовательно, он не смог бы услышать блистательной речи Кальва, а значит, - и Carmen 53 было написано не в 56 году до нашей эры.

На основании какого обвинения мог Кальв начать преследование Ватиния дабы исполнить свое вышеуказанное обещание. Очевидный ответ - «De Ambitu» ${ }^{25}$. Ведь уже в речи «Pro Sestio» Цицерон бросает Ватинию обвинение в нарушении «Lex Tullia De Ambitu» ${ }^{26}$, повторяя свои слова в «In Vatinium» 27. "qua re, cum ego legem de ambitu tulerim ex senatus consulto, tulerim sine vi, tulerim salvis auspiciis, tulerim salva lege Aelia et Fufia, tu eam esse legem non putes"28, тем

${ }^{23}$ Говард Комфорт (Howard Comfort) «The Date of Catullus 53» Haverford College. 1935. PP. 764-76

${ }^{24}$ Robinson Ellis. A commentary on Catullus. Oxford. 1876. P. XLVIII-LI.

${ }^{25}$ И.Х. Дворецкий (Латинско-русский словарь. 10-е изд. М., 2006. Стр. 52) интерпретирует «ambitus» как «хлопоты, преимущественно с противозаконными средствами, с помощью подкупа», B.A. Каретникова в своей статье «Ambitus: нелегитимные методы борьбы за магистратуры в римской Республике» подробно рассматривает возникновение и развитие законодательной и судебной практики касательно «ambitus», определяя сам термин как «беззаконное домогательство, обычно путем подкупа избирателей», а также «устройство слишком шикарных игр для народа, раздачи зерна и другой пищи». В.А. Каретникова обращает внимание на то, что «ambitus» «был главным бичом электоральных комиций поздней Республики».

${ }^{26}$ Cicero. Pro Sestio. 64.133 «qui legem meam contemnat, quae dilucide vetat gladiatores biennio quo quis petierit aut petiturus sit dare» - «ведь Ватиний не считается с моим законом, строго запрещающим устраивать бои гладиаторов на протяжении двух лет, в течение которых человек добивался или собирается добиваться государственной должности» и Cicero. Pro Sestio. 64.135 «sed habet defensiones duas: primum 'do,' inquit, 'bestiarios: lex scripta de gladiatoribus.' dicet se non gladiatores, sed unum gladiatorem dare et totam aedilitatem in munus hoc transtulisse. praeclara aedilitas! unus leo, ducenti bestiarii» - «но у него есть два оправдания: вопервых, «я, - говорит он, - выставляю бестиариев, а в законе говорится о гладиаторах». Он скажет, что выставляет не многих гладиаторов, а только одного гладиатора и что этим даром он ознаменовал весь свой эдилитет. Прекрасный эдилитет: один лев, две сотни бестиариев» латинский текст цитируется по изданию M.Tullii Ciceronis Orationes. Ex Officina Gessneriana. 1832. РР.210-211; перевод приводится по изданию Марк Туллий Цицерон. Речи в двух томах. Том II (62-43 гг. до н.э.). Издание подготовили В.О., Горенштейн, М.Е. Грабарь-Пассек. Издательство Академии Наук СССР. Москва 1962.

27 «Lex Tullia De Ambitu» Rotondi. Leges Publicae Populi Romani. Milano. 1912. P. 379.

28 «С какой стати, хотя я закон о домогательстве провел с одобрения сената, провел без применения насилия, провел при добром знамении, провел в соответствии с законами Элия и Фуфия, ты его законом не считаешь?» - перевод автора. Cicero. In Vatinium. 15.37 
более что в предстоящих выборах Ватиний претендовал на должность претора. Однако, как было описано выше, выборы 56 года до нашей эры были задержаны чередой беспорядков и состоялись лишь в январе 55 года до нашей эры $^{29}$. По их результатам Гней Помпей и Марк Лициний Красс были выбраны консулами и, чтобы противостоять своему оппоненту Марку Порцию Катону Младшему ${ }^{30}$ (которого на должность претора выдвигали оптиматы ${ }^{31}$ и которого поддерживал Цицерон), добились избрания своего кандидата ${ }^{32}$ - Публия Ватиния, разумеется, цезарианца. Очевидно, Ватиний вступил в должность незамедлительно после выборов ${ }^{33}$, таким образом обеспечив себе неприкосновенность, и, следовательно, не мог быть подвергнут какому-либо обвинению (или преследованию) до 54 года до н.э. ${ }^{34}$

Итак, из всего вышесказанного можно заключить, что процесс состоялся в 54 году до нашей эры, а сторонами в нем были Марк Туллий Цицерон, выступающий в защиту ${ }^{35}$ Публия Ватиния, и Лициний Кальв ${ }^{36}$ в качестве

${ }^{29}$ Утченко С.Л. Юлий Цезарь. - М.: Мысль, 1976. Стр. 138.

${ }^{30}$ Плутарх. Сравнительные Жизнеописания. Катон. 42, Помпей. 52; Dio 39.27, 39.30-32.

31 Представители старой аристократии, защитники авторитета сената.

32 «путем подкупа и насилия» Э.С.Грюэн (E.S. Gruen) «Last Generation» P.302 а также Плутарх. Сравнительные Жизнеописания. Помпей. 52 - «подкупленные центурии выбрали претором Ватиния».

33 Плутарх. Сравнительные Жизнеописания. Катон. 42. «Помпей и Красс... провели решение, чтобы новые преторы вступили в должность немедленно после избрания, не дожидаясь назначенного законом срока, в который обыкновенно проходили судебные дела против виновных в подкупе народа»

${ }^{34}$ Пока не закончится срок его полномочий как претора.

35 160. «Iam de sodaliciis causam dixeram P.Vatinius eodem defendente M.Cicerone» Bobiensia: Neue Beitrager Textkritik und sprache der Bobienser Ciceroscholien. Theodor Stangl. Buchdruckerei von J.B.Lindl, 1984 года. В поддержку мнения о том, что в процессе против Ватиния защитником был именно Цицерон можно также привести цитату из Блаженного Иеронима «Lege pro Vatinio oratiunculam, et alias ubi sodalitiorum mentio sit. Revolve dialogos Tullii» (Hieronymus. Adv. Rufin. 3.39)

36 Относительно участия Кальва в этом процессе как уже рассматривалось выше упоминает схолиаст из Боббио(однако он спутал даты и приписал этот процесс к 58 году до н.э.), помимо этого сохранились отсылки и фрагмент речи Кальва против Ватиния: Квинтилиан «Nam egregie in Vatinium Calvus "factum" inquit "ambitum scitis omnes, et hoc vos scire omnes sciunt» (Institutio Oratoria. Liber VI. XIII. По изданию De institutione oratoria: Cum Notis Et Animadversionibus Virorum Doctorum, Volume 1. Marcus Fabius Quintilianus, Pieter Burman De Vivie, 1720. Р. 503) - «Кальв, в речи своей против Ватиния, прекрасно сказал: Вы, судьи, знаете все, что Ватиний виноват в подкупах, и все знают, что вы об этом знаете» (Перевод 
обвинителя, предметом обвинения было нарушение «Lex Licinia de sodaliciis» ${ }^{37}$. Учитывая цитаты из речи, сохранившиеся в трудах Квинтилиана и Сенеки, высокую оценку ее Тацитом, отклик самого Ватиния, который сохранил Сенека Старший в своих «Controversiae»: «rogo vos, iudices; num, si iste disertus est, ideo me damnari oportet?» ${ }^{38}$, - можно с большой долей вероятности предположить, что именно по следам этой проникновенной речи Лициния Кальва Катулл написал Carmen 53.

приводится по изданию: Марка Фабия Квинтилиана двенадцать книг риторических наставлений. Санкт-Петербург, типография Императорской Российской Академии, 1834, часть I. Переведены с Латинского Императорской Российской Академии Членом Александром Никольским и оною Академиею изданы), Сенека «Illa hoc loco in Vatinium Calvi repetenda sententia est: 'factum esse ambitum scitis, et hoc vos scire omnes sciunt'» (Epistulae Morales ad Lucilium. 94.25 по изданию L. Annaei Senecae Ad Lucilium epistolae morales, Volume 2. Lucius Annaeus Seneca. ex typographia Societatis bipontinae, 1809. Р. 43) - «тут к месту повторить изреченье Кальва в речи против Ватиния: «Вы знаете, что подкуп был, и все знают, что вы это знаете» (перевод приводится по изданию Луций Анней Сенека. Нравственные письма к Луцилию. М., Издательство «Наука», 1977. Перевод, примечания, подготовка издания С. А. Ошерова. Отв. ред. М. Л. Гаспаров), а также Харисий (древнеримский грамматик) в своей «Ars Grammatica»: «ad pro autem Licinius Caluus in P(ublium) Vatinium ambitus reum» - «также Лициний Кальв против П(ублия) Ватиния касательно дела о домогательстве» (перевод автора).

37 «Lex Licinia de sodaliciis» - является разновидностью законов «De Ambitu». Вероятно, об этом законе идет речь у Плутарха «когда Помпей начал процессы о подкупе и лихоимстве и издал законы, на основании которых были возбуждены судебные преследования» (Сравнительные Жизнеописания. Помпей. 55. Текст приводится по изданию: Плутарх. Сравнительные жизнеописания в двух томах, М.: Издательство «Наука», 1994. Издание второе, исправленное и дополненное. Т. ІІ. Перевод Г.А. Стратановского, обработка перевода для настоящего переиздания С.С. Аверинцева, примечания М.Л. Гаспарова). В июле 54 года до н.э. по обвинению в нарушении этого же закона Цицерон защищал Гнея Планкия - «in qua tu nomine legis Liciniae, quae est de sodaliciis, omnis ambitus leges complexus es»(Pro Plancio., edited, with introd. and notes by H.W. Auden. 1897. Macmillan. London. P. IX).

${ }^{38}$ Lucius Annaei Senecae Maiores Controversiae. Liber VII. 4.6-8. «я спрашиваю вас, судьи; значит, если он красноречив, то меня следует осудить?» - перевод автора. Текст цитируется по изданию Seneca the Elder. Janet Fairweather. Cambridge University Press. 2007. P. 96. 